\title{
Impact of temperature change from admission to day one on neonatal mortality in a low-resource setting
}

Francesco Cavallin', Serena Calgaro ${ }^{2,3}$, Valentina Brugnolaro ${ }^{3}$, Amir Hussein Abubacar Seni $^{4}$, Arlindo Rosario Muhelo ${ }^{4}$, Liviana Da Dalt ${ }^{3}$, Giovanni Putoto ${ }^{2}$ and Daniele Trevisanuto ${ }^{3^{*}}$ (1)

\begin{abstract}
Background: Thermal control after birth is an essential part of neonatal care. However, the relationship between neonatal temperature at and after admission is unknown. This study aimed to evaluate the change between neonatal temperature at admission and at day 1 , and its impact on mortality.

Methods: Retrospective observational study at the Beira Central Hospital, Mozambique. Axillary temperatures were recorded at admission and at day 1 in 1,226 neonates who were admitted to the Special Care Unit between January 1 and December 31, 2017. The relationship between mortality rate and temperature change was evaluated with a matrix plot and a forest plot (obtained from a logistic regression model as odds ratios with 95\% confidence intervals).

Results: Normothermia was found in 415 neonates (33.8\%) at admission and in 638 neonates (52.0\%) at day 1. Mortality rate was highest in (i) neonates who remained in severe/moderate hypothermia (74\%), (ii) neonates who rewarmed from hypothermia (40-55\%), and (iii) neonates who chilled to severe/moderate hypothermia (38-43\%). Multivariable analysis confirmed that temperature change from admission to day 1 was an independent predictor of mortality $(p<0.0001)$.

Conclusions: In a low-resource setting, one out of three neonates was found hypothermic at day 1 irrespectively of admission temperature. Relevant thermal deviations occurred in a high proportion of newborns with normothermia at admission. Being cold at admission and becoming cold or hyperthermic at day 1 were associated with increased likelihood of mortality. Appropriate actions to prevent both hypothermia and hyperthermia represent both a challenge and a priority during postnatal period.
\end{abstract}

Keywords: Birth, Hypothermia, Low-resource setting, Mortality, Temperature

* Correspondence: daniele.trevisanuto@unipd.it

${ }^{3}$ Department of Women and Children Health, University of Padova, Via Giustiniani, 3, 35128 Padova, Italy

Full list of author information is available at the end of the article

C C The Author(s). 2020 Open Access This article is licensed under a Creative Commons Attribution 4.0 International License, which permits use, sharing, adaptation, distribution and reproduction in any medium or format, as long as you give appropriate credit to the original author(s) and the source, provide a link to the Creative Commons licence, and indicate if changes were made. The images or other third party material in this article are included in the article's Creative Commons licence, unless indicated otherwise in a credit line to the material. If material is not included in the article's Creative Commons licence and your intended use is not permitted by statutory regulation or exceeds the permitted use, you will need to obtain permission directly from the copyright holder. To view a copy of this licence, visit http://creativecommons.org/licenses/by/4.0/. The Creative Commons Public Domain Dedication waiver (http://creativecommons.org/publicdomain/zero/1.0/) applies to the data made available in this article, unless otherwise stated in a credit line to the data. 


\section{Background}

Maintaining normothermia at birth remains a major challenge in neonatal care $[1,2]$. Neonatal hypothermia contributes to mortality as comorbidity of preterm birth, asphyxia and sepsis [3], while neonatal hyperthermia is associated with brain injury and hemodynamic changes [4]. Although deviations from normothermia are common in both high- and low-resource settings, maintaining normothermia at birth is even more critical in low-resource settings, where limited availability of equipment, poor provider training and inadequate awareness of the problem impair the thermal care of the newborns $[3,5]$.

Neonatal temperature at admission plays an important role in newborn survival in both high- and low-resource settings [6]. Previous studies showed that both hypothermia and hyperthermia at admission are associated with increased likelihood of mortality [6]. Therefore, appropriate actions to prevent thermal losses immediately after birth are crucial.

Furthermore, neonatal temperature during the first days of life has also been recognized as an important prognostic factor [7], thus highlighting the importance of thermal care during an extended period after birth.

However, little is known about the relationship between neonatal temperature at and after admission. In other words, it is unclear whether normothermia at admission is followed by negligible thermal losses, or whether deviations from normothermia (i.e. hypothermia or hyperthermia) improve after admission.

This study aimed to evaluate the change between neonatal temperature at admission and at day 1 , and its impact on mortality in a low-resource setting.

\section{Methods}

\section{Study design}

This is a retrospective study about the effect of temperature at day 1 on neonatal mortality at the Special Care Unit (SCU) of the Beira Central Hospital $(\mathrm{BCH})$ in Beira (Mozambique). The Clinical Board of $\mathrm{BCH}$ approved the study and waived the need for written informed consent given the retrospective nature of the study and the use of anonymized data from hospital records. $\mathrm{BCH}$ is located in the province of Sofala, Mozambique, and is the referral hospital for a geographical area that covers about 1.7 million people. About 5, 000 deliveries and 2,100 admissions to the SCU occur every year at $\mathrm{BCH}$.

\section{Patients}

All neonates admitted to the SCU between January 1 and December 31, 2017 were evaluated for inclusion in the study. Neonates with available data on temperature at admission and at day 1 were included the study.

\section{Data collection}

All data were retrieved from hospital records by hospital staff and were collected in an anonymized dataset. Data included birthplace, mode of delivery, gestational age, sex, birth weight, twin pregnancy, 5minute Apgar score, diagnosis at admission, neonatal temperature at admission, and neonatal temperature at day 1. As the availability of laboratory and instrumental exams was limited, diagnosis at admission was based on clinical examination [8]. Neonatal axillary temperature was measured using an electronic thermometer. Severe/moderate hypothermia was defined as temperature $<36{ }^{\circ} \mathrm{C}$, mild hypothermia as $36-36.4{ }^{\circ} \mathrm{C}$, normal temperature as $36.5-37.5{ }^{\circ} \mathrm{C}$ and hyperthermia as $>37.5{ }^{\circ} \mathrm{C}[9]$.

\section{Statistical analysis}

Continuous data were reported as median and interquartile range (IQR), while categorical data as number and percentage. Correlation between continuous data was evaluated using Spearman's rank correlation coefficient (rho).

A Bland-Altman-like plot was used to graphically evaluate the distribution of the changes in neonatal temperature from admission to day 1 with respect to the temperature at admission.

The relationship between mortality rate and temperature change was evaluated with a matrix plot and a forest plot (obtained from a logistic regression model as odds ratios with $95 \%$ confidence intervals).

Multivariable analysis of mortality was performed with a logistic regression model including temperature change and a set of clinically relevant factors (jaundice/ hyperbilirubinemia, fever, trauma, wet lung, asphyxia/ HIE, sepsis/seizures, prematurity/LBW, congenital malformations, place and mode of delivery, HIV, sex, twin birth, maternal age, and number of previous gestations). The 5-minute Apgar score was not included because it was unavailable in neonates born at home. Gestational age and birth weight were included in the multivariable analysis as the clinically relevant category "prematurity/ LBW". Since all neonates born from caesarean sections were inborns, birthplace and mode of delivery were collapsed in one variable with four categories ("caesarean inborn", "vaginal inborn", "vaginal outborn" and "vaginal homebirth"). Model selection was performed by AIC reduction. In the final model, odds ratios (with 95\% confidence intervals) were calculated to describe the effects of the independent variables on mortality. Model performance was evaluated with internal validation (cindex) and calibration (calibration-in-the-large and calibration slope) using bootstrap methods (re-sampling with replacement to create 1,000 samples of the same size as the original) [10]. 
All test were 2-sided and a p-value less than 0.05 was considered statistically significant. Statistical analysis was performed using R 3.5 (R Foundation for Statistical Computing, Vienna, Austria) [11].

\section{Results}

A total of 1,344 neonates admitted to SCU from 1st January 2017 to 31st December 2017 were included in the analysis. Fifteen neonates were discharged alive within 24 hours after admission and 60 died within 24 hours after admission, while the information was not available in 8 neonates. Among the remaining 1261 neonates, neonatal temperature at day 1 was available in 1,226 neonates (97\%) who were included in the analysis. Patient characteristics are reported in Table 1.

Neonatal temperatures at admission and day 1 are shown in Fig. 1. Median neonatal temperature at admission was $36.3{ }^{\circ} \mathrm{C}\left(\mathrm{IQR} 35.9-36.9{ }^{\circ} \mathrm{C}\right.$; $\min 32.5{ }^{\circ} \mathrm{C}$, $\max$ $41.1{ }^{\circ} \mathrm{C}$ ), with severe/moderate hypothermia reported in 345 neonates $(28.1 \%)$, mild hypothermia in 339 (27.7\%), normal temperature in $415(33.8 \%)$ and hyperthermia in $127(10.4 \%)$.

Median neonatal temperature at day 1 was $36.7^{\circ} \mathrm{C}$ (IQR 36.2-37.1 ${ }^{\circ} \mathrm{C}$; min $32.7{ }^{\circ} \mathrm{C}$, $\left.\max 40.9{ }^{\circ} \mathrm{C}\right)$, with severe/

Table 1 Patient characteristics

\begin{tabular}{|c|c|c|c|c|c|}
\hline & \multicolumn{5}{|c|}{ Temperature at admission } \\
\hline & Any temperature & $\begin{array}{l}\text { Severe or moderate } \\
\text { hypothermia }\end{array}$ & Mild hypothermia & Normothermia & Hyperthermia \\
\hline No. of subjects & 1,226 & 345 & 339 & 415 & 127 \\
\hline \multicolumn{6}{|l|}{ Neonates: } \\
\hline Gestational age, weeks ab & 37 (34-39) & $36(32-38)$ & 37 (35-39) & 37 (35-39) & $39(37-40)$ \\
\hline Sex male:female ${ }^{c}$ & $686: 539$ & 192:152 & 190:149 & 229:186 & $75: 52$ \\
\hline Birth weight, grams ${ }^{\text {ac }}$ & $2450(1700-3050)$ & $1900(1440-2725)$ & $2280(1700-3000)$ & $2700(1900-3100)$ & $3000(2500-3400)$ \\
\hline Twin & $237(19.3)$ & $86(24.9)$ & $72(21.2)$ & $70(16.9)$ & $9(7.1)$ \\
\hline 5-minute Apgar score ${ }^{\text {ad }}$ & $8(6-9)$ & $7(5-8)$ & $8(6-9)$ & $8(7-9)$ & $9(8-10)$ \\
\hline \multicolumn{6}{|l|}{ Mode of delivery: ${ }^{e}$} \\
\hline Vaginal & $908(74.5)$ & $264(77.2)$ & $234(69.0)$ & $305(74.2)$ & $105(83.3)$ \\
\hline Caesarean & $310(25.5)$ & $78(22.8)$ & $105(31.0)$ & $106(25.8)$ & $21(16.7)$ \\
\hline \multicolumn{6}{|l|}{ Birthplace } \\
\hline Inborn & $688(56.1)$ & $185(53.6)$ & $220(64.9)$ & $242(58.3)$ & $41(32.2)$ \\
\hline Outborn & $451(36.8)$ & $121(35.1)$ & $104(30.7)$ & $147(35.4)$ & $79(62.2)$ \\
\hline Homebirth & $87(7.1)$ & $39(11.3)$ & $15(4.4)$ & $26(6.3)$ & $7(5.5)$ \\
\hline Total time from birth to admission, minutes af & $61(38-187)$ & $55(37-135)$ & $52(35-119)$ & $70(40-240)$ & $868(134-1580)$ \\
\hline \multicolumn{6}{|l|}{ Diagnosis at admission: } \\
\hline Asphyxia/HIE & $324(26.4)$ & $102(29.6)$ & $101(29.8)$ & $101(24.3)$ & $20(15.7)$ \\
\hline Prematurity/LBW & $409(33.4)$ & $169(49.0)$ & $122(36.0)$ & $105(25.3)$ & $13(10.2)$ \\
\hline Sepsis & $32(2.6)$ & $1(0.3)$ & $7(1.0)$ & $4(1.0)$ & $20(15.7)$ \\
\hline Fever & $50(4.1)$ & $3(0.9)$ & $0(0.0)$ & $8(1.9)$ & $39(30.7)$ \\
\hline CMs & $48(3.9)$ & $8(2.3)$ & $16(4.7)$ & $19(4.6)$ & $5(3.9)$ \\
\hline Wet lung & $118(9.6)$ & $25(7.2)$ & $30(8.8)$ & $58(14.0)$ & $5(3.9)$ \\
\hline Trauma & $9(0.7)$ & $2(0.6)$ & $2(0.6)$ & $5(1.2)$ & $0(0.0)$ \\
\hline Seizures & $12(1.0)$ & $1(0.3)$ & $2(0.6)$ & $5(1.2)$ & $4(3.1)$ \\
\hline Jaundice/ hyperbilirubinemia & $22(1.8)$ & $1(0.3)$ & $6(1.8)$ & $11(2.6)$ & $4(3.1)$ \\
\hline Other diagnoses & $202(16.5)$ & $33(9.6)$ & $53(15.6)$ & $99(23.8)$ & $17(13.4)$ \\
\hline \multicolumn{6}{|l|}{ Mothers: } \\
\hline Maternal age, years ag & $23(19-28)$ & $23(19-28)$ & $23(19-28)$ & $23(19-28)$ & $23(20-30)$ \\
\hline Number of previous gestations ${ }^{\text {ah }}$ & $2(1-4)$ & $2(1-4)$ & $2(1-4)$ & $2(1-4)$ & $2(1-3)$ \\
\hline HIV positive mother ${ }^{g}$ & $300(25.5)$ & $100(30.2)$ & $83(25.5)$ & $88(22.0)$ & $29(24.0)$ \\
\hline
\end{tabular}

Data expressed as No. (\%) or ${ }^{\text {a }}$ median (IQR)

CMs: Congenital malformations. HIE Hypoxic ischemic encephalopathy, LBW Low birth weight

Data not available in ${ }^{b} 68,{ }^{c} 1,{ }^{d} 122,{ }^{e} 8,{ }^{f} 526$ and ${ }^{g} 49$ subjects 
A

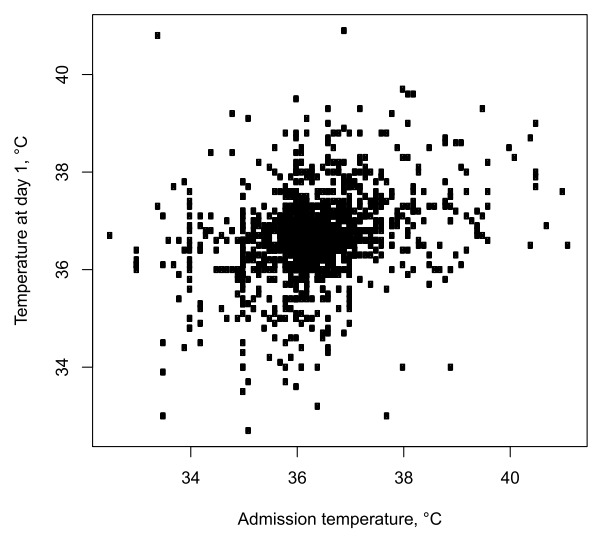

C

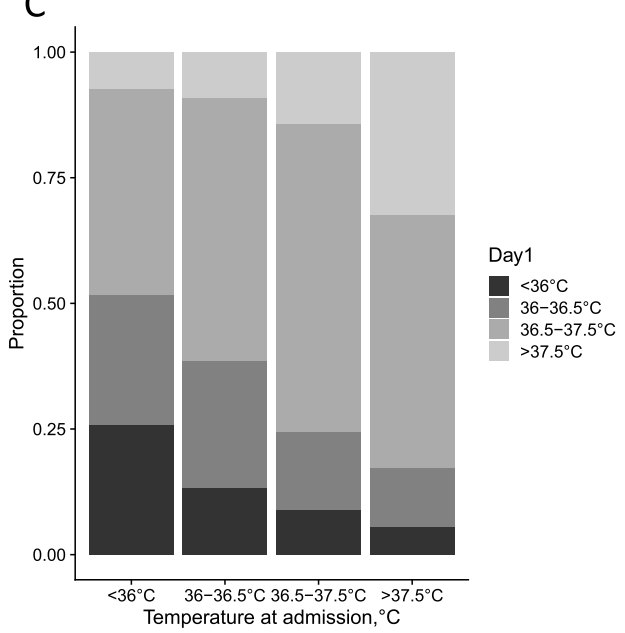

B

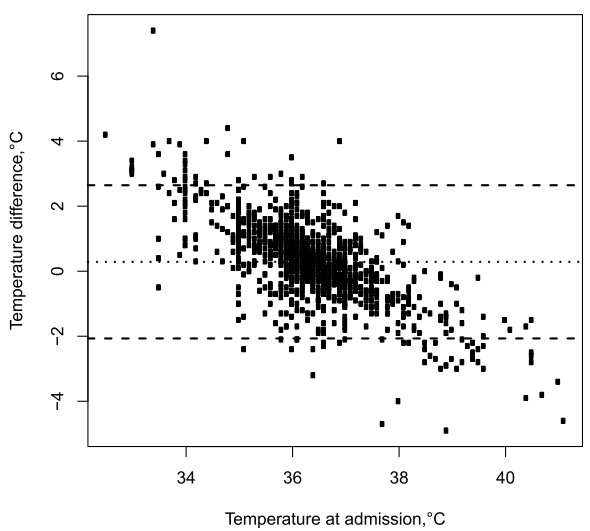

Fig. 1 Neonatal temperatures at admission and day 1: scatterplot and boxplots (a), Bland-Altman-like plot (b), and change in temperature categories (c)

moderate hypothermia reported in 178 neonates (14.5\%), mild hypothermia in 254 (20.7\%), normal temperature in $638(52.0 \%)$ and hyperthermia in 156 (12.8\%).

Neonatal temperatures at admission and at day 1 were correlated (Spearman's rho 0.31, $p<0.0001$; Fig. 1A). Mean temperature change from admission to day 1 was $0.3{ }^{\circ} \mathrm{C}$ (with $95 \%$ of data between $-2.1{ }^{\circ} \mathrm{C}$ and $2.6{ }^{\circ} \mathrm{C}$; Fig. 1B), and it was inversely correlated with temperature at admission (Spearman's rho $-0.20, p<0.0001$ ).

The association between mortality rates and temperatures at admission and day 1 are shown in Fig. 2. Mortality rate was the lowest in neonates who remained in normothermia (15\%) and in those who changed from hyperthermia at admission to normothermia/hyperthermia at day 1 (12-15\%). On the other hand, mortality rate was the highest in (i) neonates who remained in severe/moderate hypothermia (74\%), (ii) neonates who rewarmed from hypothermia (40-55\%), and (iii) neonates who chilled to severe/moderate hypothermia (3843\%) (Fig. 2A; Table 2).
Unadjusted analysis of mortality showed that hypothermia at admission was a risk factor of mortality regardless of temperature at day 1 (Fig. 2B), while neonates admitted in normothermia had increased risk of mortality in case of both hypothermia and hyperthermia at day 1 (Fig. 2B). On the other hand, changing from hyperthermia at admission to hypothermia at day 1 had an inconclusive effect of mortality due to the small sample size (22 neonates).

At multivariable analysis of mortality, temperature change from admission to day 1 , diagnosis, delivery, sex and HIV were included in the final model, while maternal age, number of previous deliveries and twin pregnancy were excluded (AIC reduction from 1169 to 1121). Temperature change from admission to day 1 $(p<0.0001)$, diagnosis $(p<0.0001)$, delivery $(p<0.0001)$ and HIV $(p=0.02)$ were associated with mortality, while sex $(p=0.13)$ did not. Odds ratio with $95 \%$ confidence intervals are reported in Table 3. Internal validation and calibration via bootstrapping showed good validation (c- 
A

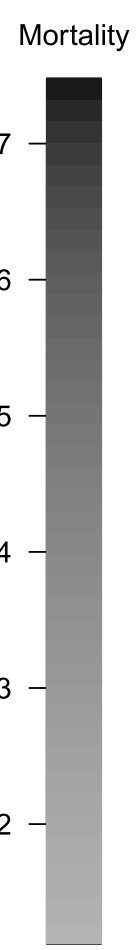

Admission

B

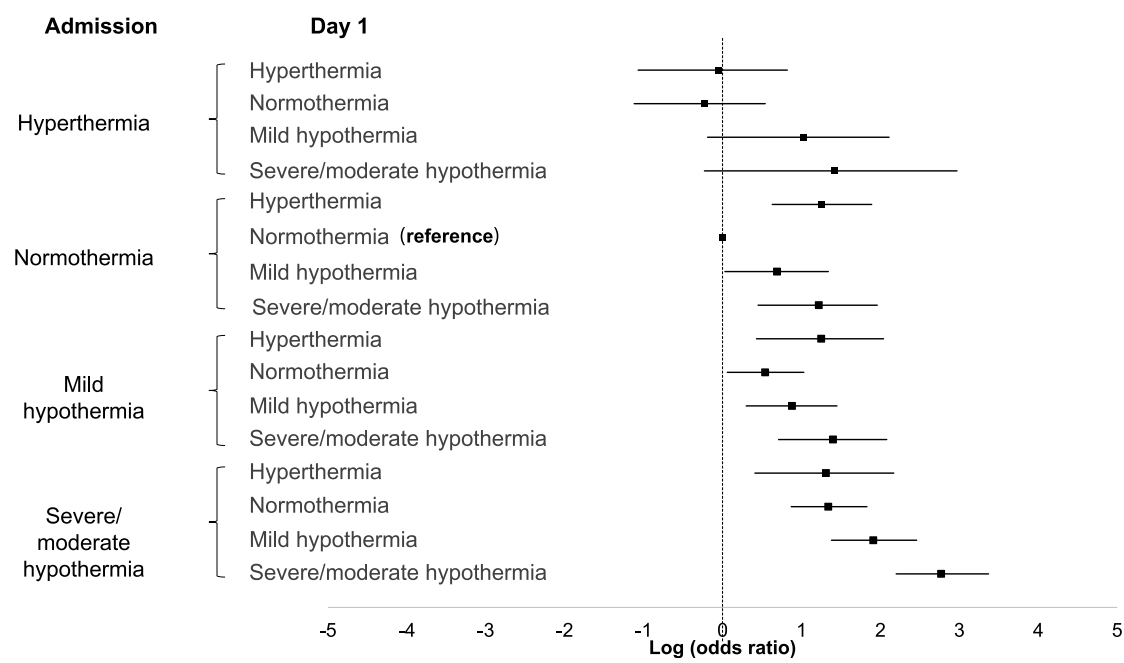

Fig. 2 Mortality rate according to change in neonatal temperatures from admission to day 1: matrix plot (a) and forest plot (with log odds ratios and $95 \%$ confidence intervals with respect to neonates who remained in normothermia) (b)

index 0.78 ) and calibration (calibration-in-the-large 0.0775 and calibration slope 0.8808 ).

\section{Discussion}

Our findings highlighted that one out of three neonates was found hypothermic at day 1 irrespectively of admission temperature. Both being cold at admission and becoming cold at day 1 were associated with increased likelihood of mortality.

To our knowledge, this is the first study investigating the relationship between temperatures at admission and at day 1, and assessing the impact of temperature change on mortality risk across a full range of neonatal temperatures in a lowresource setting. The importance of neonatal temperature at 
Table 2 Neonatal temperatures ad admission and at day 1: number of neonates and deaths (in brackets) for each category

\begin{tabular}{|c|c|c|c|c|c|}
\hline & & \multicolumn{4}{|c|}{ Neonatal temperature at admission } \\
\hline & & $>37.5^{\circ} \mathrm{C}$ & $36.5-37.5^{\circ} \mathrm{C}$ & $36-36.5^{\circ} \mathrm{C}$ & $<36{ }^{\circ} \mathrm{C}$ \\
\hline \multirow[t]{4}{*}{ Neonatal temperature at day 1} & $>37.5^{\circ} \mathrm{C}$ & 41 (6 deaths) & 59 (23 deaths) & 31 (12 deaths) & 25 (10 deaths) \\
\hline & $36.5-37.5^{\circ} \mathrm{C}$ & 64 (8 deaths) & 255 (39 deaths) & 177 (42 deaths) & 142 (58 deaths) \\
\hline & $36-36.5^{\circ} \mathrm{C}$ & 15 (5 deaths) & 64 (17 deaths) & 86 (26 deaths) & 89 (49 deaths) \\
\hline & $<36{ }^{\circ} \mathrm{C}$ & 7 (3 deaths) & 37 (14 deaths) & 4519 (deaths) & 89 (66 deaths) \\
\hline
\end{tabular}

admission is well acknowledged, with deviations from normothermia being associated with adverse neonatal outcomes [6]. Available information clearly shows an association between hypothermia and mortality, but does not distinguish whether a causal relationship with mortality exists or the temperature is only an indicator of mortality risk [12]. While the mechanisms associated with the increased mortality are unclear, it has been hypothesized that alterations of normal metabolic functions during hypothermia may lead to clinical complications such as pulmonary hypertension, hypoglycemia, hyperkalemia, impaired fluid balance, or an accumulation of toxic metabolic by-products that may not be compatible with life [13]. On the other hand, hyperthermia has been associated with life-threatening events such as neonatal seizures, hypotonia, and apnea $[1,14]$.

It is reasonable to think that the threat of deviations from normothermia does not expire after admission, thus requiring further attention during neonatal care. A previous review suggested that neonatal temperature during the first days of life can represent an important contributor to neonatal mortality in low-resource settings [7]. However, there is lack of information about the relationship between neonatal temperature at and after admission, as well as the prognostic role of temperature variation after admission. The present study adds information on this aspect, and showed that a non-negligible

Table 3 Multivariable analysis of mortality

\begin{tabular}{|c|c|c|c|c|}
\hline Variable & $p$-value & Categories & & $\begin{array}{l}\text { Odds ratio ( } 95 \% \\
\text { confidence interval) }\end{array}$ \\
\hline \multirow{5}{*}{$\begin{array}{l}\text { Temperature change from } \\
\text { admission to day } 1\end{array}$} & \multirow[t]{5}{*}{$<0.0001$} & Temperature at admission & Temperature at day 1 & - \\
\hline & & Hyperthermia & $\begin{array}{l}\text { Hyperthermia } \\
\text { Normothermia } \\
\text { Mild hypothermia } \\
\text { Severe/moderate hypothermia }\end{array}$ & $\begin{array}{l}1.08(0.33 \text { to } 3.03) \\
1.00(0.39 \text { to } 2.38) \\
3.12(0.84 \text { to } 10.56) \\
4.13(0.65 \text { to } 23.63)\end{array}$ \\
\hline & & Normothermia & $\begin{array}{l}\text { Hyperthermia } \\
\text { Normothermia } \\
\text { Mild hypothermia } \\
\text { Severe/moderate hypothermia }\end{array}$ & $\begin{array}{l}4.24(2.11 \text { to } 8.49) \\
\text { Reference } \\
2.48(1.18 \text { to } 5.09) \\
3.59(1.56 \text { to } 8.14)\end{array}$ \\
\hline & & Mild hypothermia & $\begin{array}{l}\text { Hyperthermia } \\
\text { Normothermia } \\
\text { Mild hypothermia } \\
\text { Severe/moderate hypothermia }\end{array}$ & $\begin{array}{l}3.98(1.64 \text { to } 9.45) \\
1.65(0.96 \text { to } 2.83) \\
2.17(1.15 \text { to } 4.10) \\
3.94(1.81 \text { to } 8.54)\end{array}$ \\
\hline & & Severe/moderate hypothermia & $\begin{array}{l}\text { Hyperthermia } \\
\text { Normothermia } \\
\text { Mild hypothermia } \\
\text { Severe/moderate hypothermia }\end{array}$ & $\begin{array}{l}3.45(1.29 \text { to } 8.96) \\
3.46(2.03 \text { to } 5.98) \\
6.28(3.48 \text { to } 11.51) \\
11.24(6.00 \text { to } 21.79)\end{array}$ \\
\hline Diagnosis at admission & $<0.0001$ & $\begin{array}{l}\text { Fever, trauma, jaundice/ } \\
\text { hyperbilirubinemia, other } \\
\text { Wet lung } \\
\text { Asphyxia/HIE } \\
\text { Sepsis/seizures } \\
\text { Prematurity/LBW } \\
\text { Congenital malformations }\end{array}$ & & $\begin{array}{l}\text { Reference } \\
2.66(1.37 \text { to } 5.24) \\
4.40(2.64 \text { to } 7.59) \\
5.45(2.27 \text { to } 12.89) \\
7.07 \text { (4.31 to } 12.06) \\
10.77 \text { (4.82 to } 24.57)\end{array}$ \\
\hline Sex & 0.13 & $\begin{array}{l}\text { Female } \\
\text { Male }\end{array}$ & & $\begin{array}{l}\text { Reference } \\
1.26 \text { (0.94 to 1.69) }\end{array}$ \\
\hline Delivery & $<0.0001$ & $\begin{array}{l}\text { Vaginal inborn } \\
\text { Vaginal outborn } \\
\text { Cesarean inborn } \\
\text { Vaginal homebirth }\end{array}$ & & $\begin{array}{l}\text { Reference } \\
1.35(0.95 \text { to } 1.92) \\
0.59(0.40 \text { to } 0.87) \\
2.18(1.20 \text { to } 4.03)\end{array}$ \\
\hline HIV & 0.02 & $\begin{array}{l}\text { No } \\
\text { Yes }\end{array}$ & & $\begin{array}{l}\text { Reference } \\
1.47 \text { (1.07 to 2.02) }\end{array}$ \\
\hline
\end{tabular}


proportion of neonates (one out of three) was found hypothermic at day 1 irrespectively of admission temperature. In addition, normothermia at admission was followed by relevant thermal deviations leading to four out of ten neonates shifting to hypothermia or hyperthermia at day 1. Our findings indicated that both being cold at admission and becoming cold at day 1 were risk factors for mortality. In addition, becoming hyperthermic at day 1 was also associated with increased likelihood of mortality.

The study has some limitations that should be considered when reading the results. First, it is a single-center retrospective study, thus the generalizability of the findings may be limited to similar settings. Second, diagnosis at admission was based on clinical examination due to limited availability of laboratory and instrumental exams.

Within its limitations, our findings provide useful information to clinicians and stakeholders about the importance of thermal control in the postnatal period. While the current approaches in preventing thermal deviations from normothermia usually focus on the period immediately after birth, more prolonged efforts are needed in the following postnatal period, since there is a non-negligible likelihood of hypothermia at day 1 irrespectively of admission temperature. Normothermia at admission may reasonably lead health care providers to consider the newborn at low risk of adverse outcomes. However, relevant thermal deviations are likely to occur in a high proportion of newborns with normothermia at admission, thus requiring more attention on thermal control of these subjects. Appropriate actions to prevent both hypothermia and hyperthermia during postnatal period are crucial, since being cold at admission and becoming cold or hyperthermic at day 1 were associated with increased likelihood of mortality.

Implementation of practices such as adequate room temperature, skin-to-skin contact, use of heat sources and continuous monitoring of neonatal temperature should be promoted especially in low-resource settings, where maintaining normothermia is hampered by several barriers $[3,5,15]$.

\section{Conclusions}

In a low-resource setting, one out of three neonates was found hypothermic at day 1 irrespectively of admission temperature. Relevant thermal deviations occurred in a high proportion of newborns with normothermia at admission. Being cold at admission and becoming cold or hyperthermic at day 1 were associated with increased likelihood of mortality. Appropriate actions to prevent both hypothermia and hyperthermia represent both a challenge and a priority during postnatal period.

\section{Abbreviations}

BCH: Beira Central Hospital; SCU: Special Care Unit; NICU: Neonatal intensive care unit; WHO: World Health Organization

\section{Acknowledgements}

We are grateful to the parents of babies involved in the study. We thank the medical staff and nurses of the Beira Central Hospital for their collaboration and support.

\section{Authors' contributions}

FC was responsible for the statistical design and analysis, drafted the manuscript, contributed to interpret the results, and approved the final manuscript as submitted. SC contributed to design the study, coordinated and supervised data collection, and critically reviewed the manuscript. VB contributed to design the study, collected the data collection, and critically reviewed the manuscript. SAAA and ARM contributed to design the study, supervised data collection, and critically reviewed the manuscript. LDD contributed to design the trial and to interpret the results, and critically reviewed the manuscript. GP contributed to design the study, developed the idea into a formal grant application contributed to interpret the results, and critically reviewed the manuscript. DT contributed to the study concept, study design, data interpretation, and writing of the manuscript and critically reviewed the manuscript. The authors approved the final manuscript as submitted and agree to be accountable for all aspects of the work.

\section{Funding}

This study was funded by a contribution of the of Italian Agency for Development Cooperation (grant AID 11497/CUAMM/MOZ - Healthy Newborn Project: Innovative approaches in protecting the health of the newborn in the Province of Sofala). The founder had no role in the design of the study and collection, analysis and interpretation of data and in writing the manuscript.

\section{Availability of data and materials}

The datasets used and analyzed during the current study can be available from the corresponding author on reasonable request.

\section{Ethics approval and consent to participate}

The Clinical Board of Beira Central Hospital approved the study (January 31, 2018) and granted the use of anonymized data for scientific purposes. The Clinical Board waived the need for written informed consent given the retrospective nature of the study and the use of anonymized data from hospital records.

\section{Consent for publication}

Not applicable.

\section{Competing interests}

The authors have no potential conflicts of interest to disclose.

\section{Author details}

${ }^{1}$ Independent statistician, Solagna, Italy. ${ }^{2}$ Doctors with Africa CUAMM, Padova, Italy. ${ }^{3}$ Department of Women and Children Health, University of Padova, Via Giustiniani, 3, 35128 Padova, Italy. ${ }^{4}$ Central Hospital of Beira, Beira, Mozambique.

Received: 19 June 2020 Accepted: 15 October 2020

Published online: 23 October 2020

\section{References}

1. Trevisanuto D, Testoni D, de Almeida MFB. Maintaining normothermia: Why and how? Semin Fetal Neonatal Med. 2018;23:333-9.

2. Perlman JM, Wyllie J, Kattwinkel J, Wyckoff MH, Aziz K, Guinsburg R, et al. Neonatal Resuscitation Chapter Collaborators.Part 7: neonatal resuscitation: 2015 International consensus on cardiopulmonary resuscitation and emergency cardiovascular care science with treatment recommendations. Circulation. 2015;132(16 Suppl 1):204-41.

3. Lunze K, Bloom DE, Jamison DT, Hamer DH. The global burden of neonatal hypothermia: systematic review of a major challenge for newborn survival. BMC Med. 2013;11:24.

4. Kasdorf E, Perlman JM. Hyperthermia, inflammation, and perinatal brain injury. Pediatr Neurol. 2013;49:8-14.

5. Lunze K, Hamer DH. Thermal protection of the newborn in resource-limited environments. J Perinatol. 2012;32:317-24. 
6. Lyu Y, Shah PS, Ye XY, Warre R, Piedboeuf B, Deshpandey A, et al. Canadian Neonatal Network. Association between admission temperature and mortality and major morbidity in preterm infants born at fewer than 33 weeks' gestation. JAMA Pediatr. 2015;169:e150277.

7. Mullany LC. Neonatal hypothermia in low-resource settings. Semin Perinatol. 2010:34:426-33.

8. Cavicchiolo ME, Lanzoni P, Wingi MO, Pizzol D, Daverio M, Da Dalt L, et al. Reduced neonatal mortality in a regional hospital in Mozambique linked to a Quality Improvement intervention. BMC Pregnancy Childbirth. 2016;16:366,

9. World Health Organization. Thermal Protection of the Newborn: A Practical Guide. Report No.: WHO/RHT/MSM/97.2. Geneva, World Health Organization, 1997.

10. Steyerberg EW. Clinical Prediction Models: a practical approach to development, validation, and updating. New York: Springer; 2010.

11. R Core Team. R: A language and environment for statistical computing. R Foundation for Statistical Computing, Vienna, Austria. URL https://www.Rproject.org/.

12. Laptook AR, Bell EF, Shankaran S, Boghossian NS, Wyckoff MH, Kandefer S, et al. Generic and Moderate Preterm Subcommittees of the NICHD Neonatal Research Network. Admission temperature and associated mortality and morbidity among moderately and extremely preterm infants. J Pediatr. 2018:192:53-9.e2.

13. Perlman J, Kjaer K. Neonatal and maternal temperature regulation during and after delivery. Anesth Analg. 2016;123:168-72.

14. Greenwell EA, Wyshak G, Ringer SA, Johnson LC, Rivkin MJ, Lieberman E. Intrapartum temperature elevation, epidural use, and adverse outcome in term infants. Pediatrics. 2012;129:e447-54.

15. McCall EM, Alderdice F, Halliday HL, Vohra S, Johnston L. Interventions to prevent hypothermia at birth in preterm and/or low birth weight infants. Cochrane Database Syst Rev. 2018;2:CD004210.

\section{Publisher's Note}

Springer Nature remains neutral with regard to jurisdictional claims in published maps and institutional affiliations.

Ready to submit your research? Choose BMC and benefit from:

- fast, convenient online submission

- thorough peer review by experienced researchers in your field

- rapid publication on acceptance

- support for research data, including large and complex data types

- gold Open Access which fosters wider collaboration and increased citations

- maximum visibility for your research: over $100 \mathrm{M}$ website views per year

At $\mathrm{BMC}$, research is always in progress.

Learn more biomedcentral.com/submissions 